\title{
GENDER DIFFERENCES IN MATE SELECTION: EVIDENCE FROM A SPEED DATING EXPERIMENT**
}

\author{
RAYMOND FISMAN \\ SheEna S. Iyengar \\ EMIR KAMENICA \\ ITAMAR SimONSON
}

\begin{abstract}
We study dating behavior using data from a Speed Dating experiment where we generate random matching of subjects and create random variation in the number of potential partners. Our design allows us to directly observe individual decisions rather than just final matches. Women put greater weight on the intelligence and the race of partner, while men respond more to physical attractiveness. Moreover, men do not value women's intelligence or ambition when it exceeds their own. Also, we find that women exhibit a preference for men who grew up in affluent neighborhoods. Finally, male selectivity is invariant to group size, while female selectivity is strongly increasing in group size.
\end{abstract}

\section{INTRODUCTION}

The choice of a marriage partner is one of the most serious decisions people face. In contemporary Western societies, this decision usually follows a long learning period during which people engage in more informal and often polygamous relationships, i.e., dating, which is the topic of this paper. In particular, we analyze gender differences in dating preferences. As in all matching markets, determining dating preferences from equilibrium outcomes is difficult because a given correlation of attributes across partners is often consistent with various preference structures. We overcome this problem by studying dating behavior using an experimental Speed Dating market. In our experimental paradigm, subjects meet a number of potential mates (between 9 and 21, a number determined by the experimenters) for four minutes each, and have the opportunity to accept or reject each partner. ${ }^{1}$ If both parties desire a future

\footnotetext{
* We are grateful to Lawrence Katz, Edward Glaeser, and three anonymous referees for valuable suggestions. We would also like to thank Matthew Gentzkow, David Laibson, Jesse Shapiro, and participants at seminars at Harvard University, Massachusetts Institute of Technology, and Stanford Institute for Theoretical Economics for insightful comments. Kamenica acknowledges support by the National Science Foundation Graduate Research Fellowship and the National Institute on Aging (Grant No. T32-AG00186). We are solely responsible for all mistakes.

1. Throughout the paper we will refer to the individual making the decision as subject, and the person being decided upon as partner.

๑ 2006 by the President and Fellows of Harvard College and the Massachusetts Institute of Technology.

The Quarterly Journal of Economics, May 2006
} 
meeting, each receives the other's e-mail address the following day. We emphasize that our design allows us to directly observe individual preferences (i.e., the Yes/No decisions for each partner), rather than just final matches, and furthermore, that we may control aspects of the dating "game."

We present empirical results on two dimensions of choice behavior. First, we report the valuation of attributes by men and women. Women put greater weight on intelligence than men do, while men place more value on physical appearance. Also, women put more emphasis on the partner's race. Consistent with social structure theory [Eagly and Wood 1999], we observe that a man's demand for intelligence and ambition does not extend to women who are more intelligent or ambitious than he is. In fact, a man is significantly less likely to accept a woman who is more ambitious than he. Finally, women prefer men who grew up in wealthier neighborhoods, while men express no such preference. The second element of dating choices that we study is selectivity. We find that male selectivity is invariant to the number of potential partners, while female selectivity is strongly increasing in it. Surprisingly, female subjects are no more selective than males in small groups; rather, it is the female elasticity of the number of acceptances (i.e., the number of males that a female subject wishes to meet again) with respect to group size that is lower than the male elasticity. This lower elasticity suggests that females have costs that are more convex, or benefits that are more concave, in the number of dates, relative to men.

We follow our empirical results with a brief theoretical discussion of the conditions that are needed in order to interpret our regression results on attribute valuations as reflecting underlying preferences. Essentially, we must rule out strategic behavior in partner selection.

The existing economics literature on marriage is quite rich. In his pioneering work, Becker [1973] models marriage as a frictionless matching process, and a number of recent contributions [Burdett and Coles 1997; Mortensen and Pissarides 1999; Shimer and Smith 2000; Smith 2002] extend Becker's analysis to allow for search frictions. Economists' empirical analysis of marital preferences has focused on structural estimation of these marriage models [Wong 2003; Bisin, Topa, and Verdier 2004]. In contrast to these studies, we use data on individual decisions rather than final matches. 
The recent economics literature on dating per se includes an analysis of online dating by Hitsch, Hortacsu, and Ariely [2004]. They use a large data set obtained from a dating web site to study how individual characteristics affect outcomes such as the decision to correspond via e-mail. Their preliminary findings are broadly consistent with our own: women put more weight on proxies for intelligence and income and also have a stronger preference for men of their own ethnicity.

While the literature on dating is quite new to economics, psychologists have long studied the determinants of premarriage mate choices using survey evidence (for reviews, see Regan et al. [2000]; Stewart, Stinnett, and Rosenfeld [2000]; and Buss and Kenrick [1998]). In general, research indicates that men emphasize physical attractiveness more than intelligence or ambition [Buss 1994]. Women, on the other hand, place greater emphasis on earning potential, considering such attributes as ambition, intelligence, and social status. These differences are most pronounced in mate choices for long-term relationships; thus, women place greater emphasis on physical attractiveness when selecting mates for short- than for long-term relationships [Regan 1998]. Research also indicates that both men and women consider similarity and fit in choosing a mate [Kerckhoff and Davis 1962]. Furthermore, both males and females tend to select mates of about equal social value [Murstein 1970].

There are two primary competing explanations for the differences in the selection criteria of men and women (for reviews, see Eagly and Wood [1999] and Regan et al. [2000]). Evolutionary psychologists (e.g., Buss [1989] and Kenrick and Keefe [1992]) argue that women's emphasis on mates' resource acquisition ability and men's emphasis on mates' physical attractiveness arise from different parental roles. According to Buss, male choice reflects women's time-limited reproductive capacity and the tendency of men to seek women with attributes that signal such capacity. Female choice reflects women's desire to find men who can provide resources to aid in the upbringing of their offspring.

According to social structure theory [Eagly and Wood 1999] and the closely related social role theory [Eagly 1987], gender differences in mate selection criteria derive from the differences in the social positions and roles of men and women. Thus, selection criteria may reflect a preference for individuals who fit their stereotypical gender role. Social structure theory implies that men will be less attracted to women who are superior to them on 
more male stereotypical dimensions (e.g., ambition), whereas women would tend to avoid men who are relatively more attractive than they are [Eagly and Wood 1999]. Our findings confirm the former, but not the latter, prediction.

The remainder of the paper is structured as follows. Section II describes the experimental design and the data. Section III reports the findings on the demand for attributes, and Section IV the results on selectivity. In Section V we formally establish the assumptions needed for our interpretation of the empirical results. Section VI concludes.

\section{Experimental Design and Data Description}

Our experimental design is based on meetings through Speed Dating, in which participants engage in four-minute conversations to determine whether or not they are interested in meeting each other again. If both people "accept," then each is subsequently provided with the other's contact information.

The main advantage of our design is that it gives us experimental control and yet provides us with data on decisions made in a setting very similar to that which arises in the real world. Speed Dating is a well-established format in the United States, with eight companies in 2004 devoted exclusively to this approach in New York City alone, in addition to the many online matchmaking companies that offer Speed Dating as one of their services. ${ }^{2}$ We made a special effort to ensure that our design creates a setting similar to that provided by the private firms operating in this market. The evening's "script" was based specifically on the HurryDate format, the largest Speed Dating company in New York. ${ }^{3}$

Subjects-Our subjects were drawn from students in graduate and professional schools at Columbia University. Participants were recruited through a combination of mass e-mail and fliers posted throughout the campus and handed out by research assistants. In order to sign up for the Speed Dating events, interested students had to register at an online web site on which they

2. We tried to obtain data from private firms operating in this industry but were unable to find a company willing to collaborate. Additionally, our results on the impact of the number of partners on selectivity would have been more difficult to establish without exogenous variation in group size.

3. One major difference, however, is that we did not serve alcohol to the participants. 
reported their names and e-mail addresses and completed a preevent survey.

Setting-The Speed Dating events were conducted in an enclosed room within a popular bar/restaurant near the campus. The table arrangement, lighting, and type and volume of music played were held constant across events. Rows of small square tables were arranged with one chair on either side of each table.

Procedure-The events were conducted over weekday evenings during 2002-2004; data from fourteen of these sessions are utilized in this study. ${ }^{4}$ In general, two sessions were run in a given evening, with participants randomly distributed between them. Participants were not aware of the number of partners they would be meeting at the Speed Dating event. The number of participants and dates of each session are listed in Table I. ${ }^{5}$

Upon checking in, each participant was given a clipboard, a pen, and a nametag on which only his or her ID number was written. Each clipboard included a scorecard with a cover over it so that participants' responses would remain confidential. The scorecard was divided into columns in which participants indicated the ID number of each person they met. Participants would then circle "yes" or "no" under the ID number to indicate whether they would like to see the other person again. Beneath the Yes/No decision was a listing of the six attributes on which the participant was to rate his or her partner: Attractive, Sincere; Intelligent; Fun; Ambitious; Shared Interests. ${ }^{6}$

After all participants had arrived, two hosts instructed the participants to sit at the two-person tables. The females were told to sit on one side of the tables, while the males were seated across from them. Males were instructed to rotate from table to table, so

4. We ran a total of 21 sessions. Seven have been omitted: one because we imposed a maximum number of acceptances, two because we were unable to attract sufficient participants, and four because they involved an experimental intervention where participants were asked to bring their favorite book. These four sessions were run specifically to study how decision weights and selectivity would be affected by an intervention designed to shift subjects' attention away from superficial physical attributes. The inclusion of these four sessions does not alter the results reported below; they are omitted so that the only experimental difference across sessions is group size.

5 . The number of males who attended the sessions was 202 , as indicated by Table I. However, two of these subjects did not indicate Yes or No in any of their meetings, so their decisions cannot be included in the analyses. Nonetheless, they were observed and rated by their partners, and we include these two males in our analyses of female subjects' choices.

6. A number of other responses, which we do not utilize in this paper, were also elicited from the subjects. For the complete survey, please see http:// www2.gsb.columbia.edu/faculty/rfisman/Dating_Survey.pdf 
TABLE I

Number of Participants in Each Speed Dating Session

\begin{tabular}{ccc}
\hline \hline Round \# & Women & Men \\
\hline 1 & 10 & 10 \\
2 & 16 & 19 \\
3 & 10 & 10 \\
4 & 18 & 18 \\
5 & 10 & 10 \\
6 & 16 & 16 \\
7 & 10 & 10 \\
8 & 20 & 20 \\
9 & 9 & 9 \\
10 & 21 & 21 \\
11 & 9 & 10 \\
12 & 18 & 20 \\
13 & 19 & 18 \\
14 & 14 & 10 \\
\hline \hline
\end{tabular}

that by the end of the dating event they had rotated to all of the tables, meeting all of the females. ${ }^{7}$ Each rotation consisted of four minutes during which the participants engaged in conversation. After the four minutes the Speed Dating hosts instructed the participants to take one minute to fill out their scorecards for the person with whom they were just speaking. In some events there were slightly unequal numbers of males and females, so that some subjects in these events experienced empty five-minute intervals.

The morning after the Speed Dating event, participants were sent an e-mail requesting that they complete the follow-up online questionnaire. Ninety-one percent (51 percent female, 49 percent male) of the Speed Dating participants completed this follow-up questionnaire in order to obtain their matches. Upon receipt of their follow-up questionnaire responses, participants were sent an e-mail informing them of their match results.

Data Description-The main variable of interest is the Yes/No decision of subject $i$ with respect to a partner $j$, which we denote by Decision $_{i j}$. Since our focus will be differential gender

7. This was the only asymmetry in the experimental treatment of men and women. While we would have preferred to have men and women alternate in rotating, we were advised against this by the owners of HurryDate. We believe that this experimental asymmetry is unlikely to account for the observed gender differences. 
effects, we define an indicator variable Male $_{i}$. In examining subjects' decision weights, we use the ratings filled in after each round. We limit ourselves to three of the six characteristics: attractiveness, intelligence, and ambition. We omit the remaining three characteristics primarily for brevity: our main interest is in the gender differences in preferences, and we found very similar attribute weights on the omitted characteristics. None of the results are substantively affected by the inclusion of these additional covariates. Our notation for these ratings is given by Rating $_{i j c}$, which is $i$ 's rating, on a 10-point scale, of $j$ on attribute $c \in$ \{Attractiveness, Intelligence, Ambition\}. Observations for which at least one of these ratings is missing will necessarily be omitted from the regressions. We also include results based on the average ratings of all other participants that rated $j$, which we denote by $\overline{\text { Rating }}_{-i j c}$, where the overbar represents that this is an average of ratings and the negative subscript indicates that $i$ is excluded from this average.

The pre-event survey additionally provides us with the information on partner's undergraduate institution and the ZIP code where the partner grew up. We match these variables to the log of the median SAT score in the partner's undergraduate institution, $\log (S A T)_{i}$, the log of the median income in 1990 in the ZIP code where the partner grew up, $\log (\text { Income })_{i}$, and the log population density in 1990 in that ZIP code, $\log (\text { Density })_{i}{ }^{8}$

For subjects' (as opposed to partners') attributes, we primarily rely on the self-ratings from the pre-event survey. These self-ratings are denoted by $S_{e l f}$, which is $i$ 's self-rating on attribute $c$. As an alternative, we consider the consensus view of all partners who rated $i$, which we denote by Others $_{i c}$. Finally, we use the pre-event survey to construct, for each subject-partner pair, dummy variables for whether the pair has the same field of study, SameField ${ }_{i j}$, whether they are from the same part of the world, SameRegion $i j$, and whether they are of the same race, SameRace $_{i j}$.

For our individual-level regressions, we define the number of acceptances that subject $i$ gave as Yeses ${ }_{i}$. The variable NumberOfPartners $_{i}$ denotes the number of meetings that $i$ had during the event. The fraction of partners that subject $i$ accepted is YesRate $_{i}=$ Yeses $_{i} /$ NumberOfPartners $_{i}$. YesRate $_{i}$ will be our main dependent variable for the selectivity analysis.

8. Our subjects had a median age of eleven in 1990 . 
TABLE IIa

SAMPle ChaRACTERISTICS

\begin{tabular}{lrrrr}
\hline \hline & $\begin{array}{c}\text { Number of } \\
\text { Subjects }\end{array}$ & Percentage & $\begin{array}{c}\text { Columbia graduate } \\
\text { population }\end{array}$ & Percentage \\
\hline A. Field of study & & & & \\
Business & 101 & $25.63 \%$ & 1925 & $18.21 \%$ \\
Law & 44 & $11.17 \%$ & 1530 & $14.48 \%$ \\
Service & 80 & $20.30 \%$ & 2161 & $20.45 \%$ \\
Academic & 169 & $42.89 \%$ & 4953 & $46.86 \%$ \\
Total & 394 & & 10569 & \\
B. Race & & & & \\
White & 228 & $65.52 \%$ & 3978 & $7.32 \%$ \\
Black & 22 & $6.32 \%$ & 424 & $7.18 \%$ \\
Hispanic & 31 & $8.91 \%$ & 416 & \\
Asian & 67 & $19.25 \%$ & 975 & \\
Total & 348 & & 5793 & \\
C. Region of Origin & & & & \\
North America & 287 & $73.21 \%$ & & \\
Western Europe & 32 & $8.16 \%$ & & \\
Eastern Europe & 7 & $1.79 \%$ & & \\
Central Asia & 6 & $1.53 \%$ & & \\
Middle East & 6 & $1.53 \%$ & & \\
South Asia & 10 & $2.55 \%$ & & \\
East Asia & 29 & $7.40 \%$ & & \\
Latin America & 14 & $3.57 \%$ & & \\
Africa & 1 & $0.26 \%$ & & \\
Total & 392 & & & \\
\hline \hline
\end{tabular}

Statistics for the Columbia graduate student population reflect total (part-time and full-time) enrollment, and are taken from the Statistical Abstract of Columbia University 2004, available at http://www.columbia.edu/cu/opir/abstract/enrollment_fte_2004.html. No data are available on students' countries of origin.

Table IIa provides descriptive statistics of our subjects. Where possible, we also provide statistics on the overall population of students in graduate and professional schools at Columbia University. Approximately 26 percent of the subjects study business, 11 percent study law, 20 percent are in service areas,${ }^{9}$ and 43 percent are pursuing an academic degree. This well approximates the distribution in the Columbia graduate population as a whole, though business students are somewhat overrepresented. In terms of race, our sample again very closely mirrors the overall population of Columbia graduate

9. This includes students from the School of International and Public Affairs, Teachers' College, and the School of Social Work. 
TABLE IIb

Summary Statistics

\begin{tabular}{lccccc}
\hline \hline & Mean & Std. dev. & Min & Max & Obs \\
\hline Decision & 0.43 & 0.49 & 0.00 & 1.00 & 6276 \\
Same Race & 0.49 & 0.50 & 0.00 & 1.00 & 4942 \\
Same Field & 0.35 & 0.48 & 0.00 & 1.00 & 6102 \\
Same Region & 0.55 & 0.50 & 0.00 & 1.00 & 6024 \\
SAT & 1290.89 & 126.04 & 990 & 1490 & 117 \\
Income & 46056.30 & 17661.54 & 8607 & 109031 & 272 \\
Density & 13822.22 & 26696.63 & 5.89 & 122193.90 & 272 \\
\hline \hline
\end{tabular}

Decision is an indicator variable that takes on a value of one if a subject desired contact information for a partner. SAT is the median SAT score in 2003 of the partner's undergraduate institution. Income is the median income of the partner's ZIP code in 1990, measured in dollars, based on United States census data. Density is the population density of the partner's ZIP code in 1990, measured in people per square mile, based on United States census data. Same Region is an indicator variable denoting that the subject and partner were born in the same region of the world (North America, Western Europe, Eastern Europe, Central Asia, Middle East, South Asia, East Asia, Latin America, or Africa). Same Field is an indicator variable denoting that the subject and partner are in the same graduate school (aggregated to Business, Law, Service, and Academic). Same Race is an indicator variable denoting that the subject and partner are of the same race. For Same Race, Same Field, and Same Region, the level of observation is a subject-partner meeting. For SAT, Income, and Density, the level of observation is the partner.

and professional students. Finally, the majority (nearly threequarters) of our subjects grew up in North America (i.e., the United States and Canada).

Table IIb reports summary statistics on the subject's decision, the median SAT score in the partner's undergraduate institution, and the median income and the population density in 1990 in the ZIP code where the partner grew up (for partners from the United States). Of all meetings, 49 percent were between individuals of the same race, 35 percent between individuals in the same field of study, and 55 percent between individuals from the same region.

Our primary interest is understanding the desirability of these attributes, which is the goal of the next section.

\section{Results on Attribute Demand}

In this section we investigate the demand for partner's attributes. Throughout the analysis we assume that the subjects engage in straightforward behavior, i.e., that subjects are more likely to accept partners whom they like better. In the theory section, Proposition 1 lays out the conditions that are sufficient to justify this assumption. 
TABLE III

Gender Differences in Subjective Attribute Weights

\begin{tabular}{|c|c|c|c|c|c|c|}
\hline & (1) & (2) & (3) & (4) & (5) & (6) \\
\hline Ambition & $\begin{array}{l}0.013^{* *} \\
(0.007)\end{array}$ & $\begin{array}{c}0.013^{*} \\
(0.007)\end{array}$ & $\begin{array}{l}0.013^{* *} \\
(0.007)\end{array}$ & $\begin{array}{c}0.003 \\
(0.021)\end{array}$ & $\begin{array}{c}0.020 \\
(0.020)\end{array}$ & $\begin{array}{c}0.003 \\
(0.021)\end{array}$ \\
\hline Attractiveness & $\begin{array}{l}0.119 * * * \\
(0.005)\end{array}$ & $\begin{array}{l}0.140 * * * \\
(0.005)\end{array}$ & $\begin{array}{l}0.119 * * * \\
(0.005)\end{array}$ & $\begin{array}{l}0.136^{* * * *} \\
(0.008)\end{array}$ & $\begin{array}{l}0.159^{* * * *} \\
(0.010)\end{array}$ & $\begin{array}{l}0.136 * * * \\
(0.008)\end{array}$ \\
\hline Intelligence & $\begin{array}{l}0.045^{* * *} \\
(0.007)\end{array}$ & $\begin{array}{l}0.023 * * * \\
(0.008)\end{array}$ & $\begin{array}{l}0.045^{* * * *} \\
(0.007)\end{array}$ & $\begin{array}{l}0.044^{* *} \\
(0.019)\end{array}$ & $\begin{array}{c}0.005 \\
(0.022)\end{array}$ & $\begin{array}{l}0.044^{* *} \\
(0.019)\end{array}$ \\
\hline $\begin{array}{c}\text { Ambition } \\
* \text { Male }\end{array}$ & & & $\begin{array}{c}-0.001 \\
(0.009)\end{array}$ & & & $\begin{array}{c}0.016 \\
(0.029)\end{array}$ \\
\hline $\begin{array}{l}\text { Attractiveness } \\
\quad * \text { Male }\end{array}$ & & & $\begin{array}{l}0.020 * * * \\
(0.007)\end{array}$ & & & $\begin{array}{c}0.023^{*} \\
(0.013)\end{array}$ \\
\hline $\begin{array}{l}\text { Intelligence } \\
* \text { Male }\end{array}$ & & & $\begin{array}{c}-0.022^{* *} \\
(0.011)\end{array}$ & & & $\begin{array}{c}-0.039 \\
(0.029)\end{array}$ \\
\hline Subject's gender & Female & Male & Both & Female & Male & Both \\
\hline Rating measure & \multicolumn{3}{|c|}{ OwnRatings } & \multicolumn{3}{|c|}{ Consensus } \\
\hline Observations & 2655 & 2712 & 5367 & 3128 & 3128 & 6256 \\
\hline$R^{2}$ & 0.52 & 0.53 & 0.53 & 0.38 & 0.41 & 0.40 \\
\hline
\end{tabular}

Linear probability model; robust standard errors in parentheses, clustered by partner. The level of observation is a subject-partner meeting. The dependent variable in all regressions is Decision, an indicator variable that takes on a value of one if a subject desired contact information for a partner. In columns (1)-(3) the independent variables are the ratings that the subject assigned to the partner for Ambition, Attractiveness, and Intelligence. The ratings were on a 1-10 Likert Scale. In columns (4)-(6) the independent variables are the average ratings of a partner by all other subjects. Male is an indicator variable denoting whether the subject is male. All regressions include subject fixed effects, and all observations are weighted by the inverse of the number of observation per subject. * significant at 10 percent; ** significant at 5 percent; *** significant at 1 percent.

We first consider regressions of the form,

$$
\text { Decision }_{i j}=\alpha_{i}+\sum_{c \in C} \beta_{c} * \text { Rating }_{i j c}+\varepsilon_{i j},
$$

where $C=$ Attractiveness, Intelligence, Ambition $\}$. We include a subject fixed-effect $\alpha_{i}$ to control for individual-level heterogeneity. We use a linear probability model for ease of interpretation; similar results are obtained with a conditional logit model. Finally, observations are weighted by the inverse of NumberOfPart$n^{n} s_{i}$ so that subjects making more decisions are not overweighted in calculating average preference weights. The basic results, by gender, are shown in Table III, columns (1) and (2). There is a clear difference in the attribute weights on attractiveness and intelligence: males put more weight on physical attrac- 
tiveness than females do, while females put more weight on intelligence. This is consistent with the predictions of both the evolutionary and social structure theories of mate selection described in the introduction.

The magnitudes of these differences are large. Each additional attractiveness point (on a 10-point scale) increases male likelihood of saying Yes by 2.1 percentage points more than it increases the female likelihood of saying Yes. This implies that the effect of physical attractiveness is 18 percent higher for males. The implied effect of intelligence on the probability of Yes is 4.6 percentage points for women compared with 2.3 percentage points for men. We look at the statistical significance of these differences in column (3), where we pool all subjects and include an interaction term Rating*Male for each attribute; for both attractiveness and intelligence, the interaction term is significant at the 5 percent level. We do not observe any difference across genders in the importance of ambition. When we repeat the same exercise using the average of all subjects other than $i$, i.e., $\overline{\text { Rating }}_{-i j c}$, as the measure of partner attributes, we obtain qualitatively similar results (reported in columns (4)-(6) of Table III). ${ }^{10}$ Hence, the results are not driven by idiosyncratic assessments of the attributes.

We next consider the influence of subjects' own attributes on the demand for particular partners. Specifically, we examine whether subjects are averse to choosing partners who are superior to them on gender stereotypical attributes, as suggested by social structure theory [Eagly and Wood 1999]. ${ }^{11}$ We define an indicator variable, $\left(\right.$ Rating $\left._{i j c}>S e l f_{i c}\right)$, that takes on a value of one if subject $i$ 's rating of partner $j$ on attribute $c$ is greater than the subject's own attribute rating. Our specification examines the impact of the difference in the attributes $\left(\right.$ Rating $_{i j c}-S_{e l f}$ ), allowing for the effect to change when the difference is positive:

10. The gender difference in the importance of intelligence is no longer significant at conventional levels ( $p$-value $=0.14$ ).

11. The idea that men, in particular, dislike overly intelligent and ambitious women abounds in the popular press as well. For a recent example, see Dowd [2005]. 
TABLE IV

Effect of Own Attributes on Subjective Attribute Weights

\begin{tabular}{|c|c|c|c|c|}
\hline & (1) & (2) & (3) & (4) \\
\hline Ambition & $\begin{array}{c}0.009 \\
(0.008)\end{array}$ & $\begin{array}{l}0.031 * * * \\
(0.008)\end{array}$ & $\begin{array}{l}0.020 * * \\
(0.010)\end{array}$ & $\begin{array}{l}0.030 * * * \\
(0.009)\end{array}$ \\
\hline $\begin{array}{l}\text { Ambition } \times(\text { Ambition }>\text { Own } \\
\text { Ambition })\end{array}$ & $\begin{array}{c}0.012 \\
(0.014)\end{array}$ & $\begin{array}{l}-0.058 * * * \\
(0.013)\end{array}$ & $\begin{array}{r}-0.012 \\
(0.016)\end{array}$ & $\begin{array}{l}-0.047 * * * \\
(0.016)\end{array}$ \\
\hline Attractiveness & $\begin{array}{l}0.113^{* * *} \\
(0.006)\end{array}$ & $\begin{array}{l}0.134^{* * * *} \\
(0.007)\end{array}$ & $\begin{array}{l}0.097 * * * \\
(0.008)\end{array}$ & $\begin{array}{l}0.136^{* * * *} \\
(0.009)\end{array}$ \\
\hline $\begin{array}{l}\text { Attractiveness } \times \text { (Attractiveness } \\
>\text { Own Attractiveness })\end{array}$ & $\begin{array}{c}0.023 \\
(0.015)\end{array}$ & $\begin{array}{c}0.014 \\
(0.013)\end{array}$ & $\begin{array}{l}0.060^{* * * *} \\
(0.015)\end{array}$ & $\begin{array}{c}0.006 \\
(0.014)\end{array}$ \\
\hline Intelligence & $\begin{array}{l}0.049 * * * \\
(0.009)\end{array}$ & $\begin{array}{l}0.030 * * * \\
(0.009)\end{array}$ & $\begin{array}{l}0.041 * * * \\
(0.011)\end{array}$ & $\begin{array}{l}0.044^{* * * *} \\
(0.010)\end{array}$ \\
\hline $\begin{array}{c}\text { Intelligence } \times \text { (Intelligence }> \\
\text { Own Intelligence })\end{array}$ & $\begin{array}{c}-0.007 \\
(0.019)\end{array}$ & $\begin{array}{c}-0.043^{* *} \\
(0.018)\end{array}$ & $\begin{array}{c}0.007 \\
(0.018)\end{array}$ & $\begin{array}{l}-0.064 * * * \\
(0.020)\end{array}$ \\
\hline Subject's gender & Female & Male & Female & Male \\
\hline Own attribute measure & \multicolumn{2}{|c|}{ Self-rating } & \multicolumn{2}{|c|}{ Partnerconsensus } \\
\hline $\begin{array}{l}\text { Observations } \\
R^{2}\end{array}$ & $\begin{array}{l}2985 \\
0.47\end{array}$ & $\begin{array}{l}2978 \\
0.50\end{array}$ & $\begin{array}{l}3031 \\
0.33\end{array}$ & $\begin{array}{l}3016 \\
0.50\end{array}$ \\
\hline
\end{tabular}

Linear probability model; robust standard errors in parentheses, clustered by partner. The level of observation is a subject-partner meeting. The dependent variable in all regressions is Decision, an indicator variable that takes on a value of one if a subject desired contact information for a partner. Ambition, Attractiveness, and Intelligence are the ratings that a subject assigned to a partner for each of the attributes. (Ambition > Own Ambition) is an indicator variable that takes on a value of one if the subject's rating of the partner's ambition is greater than the subject's own ambition. In columns (1) and (2) the measure of subject ambition is a subject's pre-experiment self-rating; in columns (3) and (4) the measure of subject ambition is the average rating by all partners that the subject met. Similar pairs of independent variables are defined for Attractiveness and Intelligence. All regressions include subject fixed effects, and all observations are weighted by the inverse of the number of observation per subject. * significant at 10 percent; ** significant at 5 percent; *** significant at 1 percent.

$$
\begin{aligned}
\text { Decision }_{i j} & =\alpha_{i}+\sum_{c \in C} \beta_{c 0} *\left(\text { Rating }_{i j c}-\text { Self }_{i c}\right) \\
& +\sum_{c \in C} \beta_{c 1} *\left(\text { Rating }_{i j c}-\text { Self }_{i c}\right) *\left(\text { Rating }_{i j c}>\text { Self }_{i c}\right)+\varepsilon_{i j} .
\end{aligned}
$$

The results are reported in Table IV, columns (1) and (2). For attractiveness, the interaction term is insignificant for both men and women. For ambition, however, the interaction term is insignificant for females but is significantly negative $(p<0.01)$ for males. Furthermore, the effect of an increase in ambition above a man's own level, given by the sum of the direct effect and the interaction term, is negative. In other words, men strictly prefer women with their own level of ambition to women more ambitious 
than they are. A two-tailed test on the significance of the sum of the coefficient reveals that this effect is statistically significant $(p<0.05)$. The results on intelligence are qualitatively similar to those on ambition: no slope change for females while for males the slope change at the self-rated level is significant; additionally, the implied effect of increased intelligence above a man's selfrated level (given by the sum of the two coefficients) is negative, though insignificantly so. When we use Other $_{i c}$ (i.e., the average rating of subject $i$ by his partners on characteristic $c$ ) in place of Self $f_{i c}$ in columns (3) and (4), we obtain similar results. ${ }^{12}$ Hence, we demonstrate that on average men do not value women's intelligence or ambition when it exceeds their own; moreover, a man is less likely to select a woman whom he perceives to be more ambitious than he is.

One concern with the interpretation of our estimates in Tables III and IV is that men's avoidance of more intelligent or ambitious women could be due to fear of rejection by these higher quality women. However, a benefit of using the Speed Dating format is that there in no direct personal feedback, which likely mitigates any psychic cost of rejection. Further, we note that it is unclear why a gender asymmetry in rejection concerns should exist. Finally, our results are unaffected by the inclusion of the partner's Yes/No decision as a control.

A second concern is that we asked subjects to rate their partners on particular attributes at the same time that we required them to make the Yes/No decision. As research in psychology demonstrates [Wilson and Schooler 1991; Simonson and Nowlis 2000], the request to articulate reasons for a particular decision may affect the decision itself. Note that since we are primarily interested in gender differentials in attribute weights, in order for our results to be attributable to an "articulation effect" it must also be the case that there is a gender difference in the articulation effect itself. While this may be unlikely, it is not impossible, and is an important caveat in interpreting our results. For example, women may have a stronger need than men to see themselves as valuing attributes such as intelligence, and asking subjects to provide ratings on intelligence

12. One exception is the increased attention to attractiveness that women exhibit toward more attractive men.

Because of concerns that our results here may simply be picking up nonlinearities in the effect of intelligence and ambition, we also repeated these regressions including quadratic terms for these attributes; this does not impact the threshold effect. 
may force women to directly confront the need to align choices with a desired self-image. ${ }^{13}$

This concern about reason-based choice does not apply to our next set of results, ${ }^{14}$ where we examine attribute valuations based on objective characteristics that subjects were never asked to rate. We first look at the impact of intelligence (measured by the median SAT score in subject's college), economic background (measured by the median income in 1990 in the ZIP code where the subject grew up), and rusticity (measured by the population density in 1990 in that ZIP code). Unfortunately, we obtained subjects' undergraduate institution only in the final six rounds, and we possess income and population density information only for subjects who grew up in the United States (and who responded to the survey question on ZIP code). As a result, including all variables simultaneously drastically reduces the sample size. Hence, we run two separate regressions, one that relies on college information and one that uses the ZIP codes:

$$
\begin{aligned}
& \text { Decision }_{i j}=\beta_{0} * \log (S A T)_{j}+\varepsilon_{i j}, \\
& \text { Decision }_{i j}=\beta_{0} * \log (\text { Income })_{j}+\beta_{1} * \log (\text { Density })_{j}+\varepsilon_{i j} .
\end{aligned}
$$

We run these regressions separately for men and women and on the full sample with a gender interaction term. Table $\mathrm{V}$ reports the results. The first three columns support our previous finding on the effect of partner's intelligence: women put a greater emphasis on the SAT scores. This difference, as embodied in the interaction term in column (3), is significant at the 10 percent level. Further, in columns (4) through (6) we find that the coefficient on $\log$ (Income $)$ is significant only for women. While the difference between coefficients is large ( 0.08 versus 0.014$)$, the interaction $\log ($ Income $) *$ Male in column (6) is not significant ( $p$ value $=0.31$ ). For both men and women, the coefficient on log(Density) is significantly negative, while the interaction with Male is not significantly different from zero. Thus, we find tentative evidence that women prefer partners from more affluent neighborhoods, and both men and women are more likely to accept a partner who grew up in a less densely populated area.

13. Ideally, we would repeat the experiment, eliminating the attribute ratings for a random subset of subjects in each session in order to assess the importance of articulation effects. Unfortunately, it is practically infeasible to do so.

14. With the exception of results on the SAT scores. 
TABLE V

Partners' ObJective Characteristics and SubJeCts' Decisions

\begin{tabular}{lcccccc}
\hline \hline & $(1)$ & $(2)$ & $(3)$ & $(4)$ & $(5)$ & $(6)$ \\
\hline $\log$ (SAT) & $0.681^{* *}$ & -0.101 & $0.681^{* *}$ & & & \\
& $(0.293)$ & $(0.289)$ & $(0.288)$ & & & \\
$\log$ (Income) & & & & $0.088^{*}$ & 0.014 & $0.088^{*}$ \\
& & & & $(0.053)$ & $(0.052)$ & $(0.052)$ \\
$\log$ (Density) & & & & $-0.020^{*}$ & $-0.022^{* *}$ & $-0.020^{*}$ \\
& & & & $(0.011)$ & $(0.010)$ & $(0.011)$ \\
$\log$ (SAT) & & & $-0.782^{*}$ & & & \\
$\quad *$ Male & & & $(0.409)$ & & & -0.074 \\
$\log$ (Income) & & & & & & \\
$\quad *$ Male & & & & & & $-0.074)$ \\
$\log$ (Density) & & & & & & $(0.015)$ \\
$\quad *$ Male & & & & & & \\
\hline Subject's gender & Female & Male & Both & Female & Male & Both \\
Observations & 794 & 1120 & 1914 & 1915 & 2410 & 4325 \\
$R^{2}$ & 0.32 & 0.27 & 0.29 & 0.28 & 0.30 & 0.30 \\
\hline
\end{tabular}

Linear probability model; robust standard errors in parentheses, clustered by partner. The level of observation is a subject-partner meeting. The dependent variable in all regressions is Decision, an indicator variable that takes on a value of one if a subject desired contact information for a partner. Log(SAT) is the logarithm of the median SAT score in 2003 of the partner's undergraduate institution. $\log (\operatorname{Income})$ is the logarithm of median income of the partner's ZIP code in 1990, measured in dollars, based on United States census data. Log(Density) is the logarithm of the population density of the partner's ZIP code in 1990 measured in people per square mile, based on United States census data. Male is an indicator variable denoting whether a subject is male. All regressions include subject fixed effects, and all observations are weighted by the inverse of the number of observation per subject. * significant at 10 percent; ** significant at 5 percent; $* * *$ significant at 1 percent.

We do not have a well-grounded explanation for the latter effect. It may be the case that, conditioning on being a graduate student at Columbia University, people from more rural areas are systematically different in terms of income, intelligence, or some other attribute so that population density simply picks up an omitted variable. Alternatively, it could be that people from rural areas are in fact more desirable. ${ }^{15}$

Finally, we look at the importance of similarity. We consider regressions of the form,

$$
\begin{aligned}
& \text { Decision }_{i j}=\beta_{0} * \text { SameRace }_{i j}+\beta_{1} * \text { SameField }_{i j} \\
&+\beta_{2} * \text { SameRegion }_{i j}+\varepsilon_{i j} .
\end{aligned}
$$

15. We find that $\log ($ Density $)$ is correlated with attractiveness but with no other variable. 
TABLE VI

Partner-Subject Similarity and SubJects' Decisions

\begin{tabular}{lccc}
\hline \hline & $(1)$ & $(2)$ & $(3)$ \\
\hline Same Race & $0.143^{* * *}$ & 0.053 & $0.143^{* * * *}$ \\
& $(0.024)$ & $(0.032)$ & $(0.024)$ \\
Same Field & 0.002 & 0.035 & 0.002 \\
& $(0.028)$ & $(0.026)$ & $(0.028)$ \\
Same Region & $0.075^{* *}$ & $0.096^{* *}$ & $0.075^{* *}$ \\
& $(0.033)$ & $(0.043)$ & $(0.032)$ \\
Same Race & & & $-0.090^{* * *}$ \\
*Male & & & $(0.040)$ \\
Same Field & & & 0.033 \\
*Male & & & $0.038)$ \\
Same Region & & & 0.021 \\
*Male & Female & Male & $(0.054)$ \\
\hline Subject's gender & 2417 & 2417 & Both \\
Observations & 0.26 & 0.27 & 4834 \\
$R^{2}$ & & & 0.28 \\
\hline
\end{tabular}

Linear probability model; robust standard errors in parentheses, clustered by partner. The level of observation is a subject-partner meeting. The dependent variable in all regressions is Decision, an indicator variable that takes on a value of one if a subject desired contact information for a partner. Same Region is an indicator variable denoting that the subject and partner were born in the same region of the world (North America, Western Europe, Eastern Europe, Central Asia, Middle East, South Asia, East Asia, Latin America, or Africa). Same Field is an indicator variable denoting that the subject and partner are in the same area of study (aggregated to Business, Law, Service, and Academic). Same Race is an indicator variable denoting that the subject and partner are of the same race. Male is an indicator variable denoting whether the subject is male. All regressions include subject fixed effects, and all observations are weighted by the inverse of the number of observation per subject. * significant at 10 percent; ** significant at 5 percent; *** significant at 1 percent.

The results are in Table VI. Women strongly discriminate on the basis of race. They are more than 14 percentage points more likely to accept a partner of their own race. Given the underlying YesRate of 38 percent, this is a large effect. Men, on the other hand, do not exhibit a significant racial preference. Whether this difference stems from gender-specific dating goals or reflects a more fundamental gender difference is difficult to ascertain from our data. ${ }^{16}$ Being in the same field of study has no predictive power, but both men and women prefer partners from the same region of the world. We have also considered whether, for subjects from the United States, being from the same region of the country or from ZIP codes that are closer to one another increases desirability, but found no effect. In summary, our main result on

16. We analyze racial preferences in greater detail in Fisman et al. [2005]. 
similarity is that women exhibit strong preference for partners of their own race, while men do not.

In the pre-event survey, our subjects rated their interest in seventeen activities (sports, watching television, art, music, etc.) on a 10-point Likert scale. We used these responses to generate a variable SharedInterests, given by the correlation between a subject's and partner's interests in these activities. We found that SharedInterests was positively correlated with men's decisions but not with women's decisions. However, this effect disappears if we control for physical attractiveness or if we omit sports-based activities from the calculation of the correlation. The explanation seems to be that most men express a strong interest in sports, while for women, attractiveness is highly correlated with physical activity and thus by extension with an interest in sports.

\section{Results on Selectivity}

Both evolutionary theory [Symons 1979; Clark and Hatfield 1989; Buss and Schmitt 1993] and common perceptions ${ }^{17}$ suggest that women are more selective than men. We find, however, that the gender difference in selectivity crucially depends on group size. In smaller sessions (fewer than fifteen partners), selectivity is virtually identical for men and women, with subjects of each gender saying Yes to about half of their partners. In larger sessions, however, male selectivity is unchanged, while females become significantly more selective, choosing a little more than a third of their partners. Note from Table I that the distribution of group size is bimodal, so we cannot be sure whether selectivity responds uniformly to the number of partners. Nonetheless, we try to take full advantage of the limited variation in group size by considering the regression,

$$
\text { YesRate }_{i}=\beta_{0}+\beta_{1} * \text { NumberOfPartners }{ }_{i}+\varepsilon_{i} .
$$

Columns (1) and (2) of Table VII report the results by gender: females become significantly more selective in larger groups; males do not.

The coefficient on female selectivity implies that if the number of potential partners doubles from ten to twenty, the fraction

17. An evocative portrayal of this is given by an old New Yorker cartoon with a group of men and a group of women at opposite ends of a bar. A thought balloon above the men gives their collective thoughts as, "Select All," while a thought balloon above the women shows the females thinking, "Select None." 
TABLE VII

Effect of Group Size on Selectivity

\begin{tabular}{lccc}
\hline \hline & $(1)$ & $(2)$ & $(3)$ \\
\hline Group size & $-0.013^{* *}$ & 0.003 & -0.036 \\
Male & $(0.005)$ & $(0.005)$ & $(0.036)$ \\
& & & $-0.166^{*}$ \\
Group size* & & & $0.092)$ \\
$\quad$ Male & & & $0.018^{* *}$ \\
Subject's gender & Female & Male & Both \\
Round FE & No & No & Yes \\
\hline Observations & 200 & 200 & 400 \\
$R^{2}$ & 0.05 & 0.00 & 0.11 \\
\hline
\end{tabular}

Robust standard errors are in parentheses. Regressions are at the subject level. The dependent variable in all regressions is the fraction of partners for whom the subject desired contact information. Group size is the number of meetings experienced by a subject. Male is an indicator variable denoting whether the subject is male. * significant at 10 percent; ** significant at 5 percent; *** significant at 1 percent.

of partners selected declines by 13 percentage points. This reflects a decline of more than 25 percent. As an alternative specification we pool the full sample and look at

$$
\begin{aligned}
\text { YesRate }_{i}= & \beta_{\text {round }}+\beta_{1} * \text { NumberOfPartners }_{i} \\
& +\beta_{2} * \text { Male }_{i} * \text { NumberOfPartners }_{i}+\beta_{3} * \text { Male }_{i}+\varepsilon_{i} .
\end{aligned}
$$

In this formulation, $\beta_{\text {round }}$ is a round fixed effect. ${ }^{18}$ Table VII, column (3), reports the results. They are qualitatively similar to those generated by the sample split, though the implied gender differential in sensitivity to group size is even stronger.

These results have implications that are quite distinct from the average difference in selectivity, suggesting rather a more rapidly diminishing returns to dates for females. Note that if women simply had a higher cost of each date, we would not expect to see any gender difference in the relationship between selectivity and the number of partners. The observed gender asymmetry suggests that females have a more concave benefit function or a more convex cost function over the number of dates, relative to males. Moreover, the fact that male selectivity is invariant to

18. Due to slight gender imbalances in some sessions, NumberOfPartners ${ }_{i}$ is not fully absorbed by these fixed effects. 
group size indicates that they may have linear benefit and cost functions. ${ }^{19}$ Possible reasons why women's costs of going on dates may be convex are many. Great attention paid to each date, coupled with a finite time budget, is a plausible source of convexity. Social stigma may be another. Explanations for why women could have more concave benefit functions may stem from different motivations in the dating search process for the two genders.

Alternatively, the gender difference in the relationship between selectivity and group size may stem from asymmetric costs of reneging on a match, rather than asymmetric utility functions over dates. Specifically, the observed difference may arise from the social roles of men and women in setting up dates. That is, a man reneges on a match by not contacting a woman (omission), while a woman reneges by actively saying no to a man (commission). ${ }^{20}$ This may credibly create an asymmetric cost of reneging on a match. However, such cost asymmetry alone merely predicts that the level of selectivity will be higher for women than for men: if the cost of declining dates is linear, the elasticity of selectivity with respect to group size would be the same for men and women even with gender-specific reneging costs. There is no clear intuition that suggests that this cost should be convex, and it could very easily be the opposite (one grows inured to the psychological trauma of rejecting others). That said, with the data we have, it is not possible to completely rule out this possibility.

A second alternative is the potential gender difference in fear of rejection discussed in Section III. As we note there, one benefit of using the Speed Dating format is that there is no direct personal feedback, which likely mitigates any psychic cost of rejection. Additionally, we may control to some degree for fear of rejection by including the average rejection rate for each subject as a control variable in our regressions on group size. We find that its inclusion has little effect on the coefficient on NumberOfPartners.

Finally, since sessions with more partners are necessarily longer, we investigated whether the probability that a subject

19. One may think that the Speed Dating sessions have a minimal impact on each subject's overall dating opportunities, so that the number of partners ought to be irrelevant for selectivity regardless of the second derivative properties of the utility function. Our surveys reveal, however, that the matches formed at the experimental sessions constitute a major component of the subjects' dating experiences. More importantly, as the results make clear, group size does in fact significantly influence selectivity of our female subjects.

20 . Our follow-up survey indicates that roughly half of the matches resulted in actual dates. Further, 64 percent of the men initiated contact with at least one match compared with only 17 percent of the women. 
says Yes changes over the course of the Speed Dating session. The only time trend in the data is that women are significantly more likely to say Yes in their first meeting, both in the small and in the large groups. We have no explanation for this, and believe it may be a statistical artifact. ${ }^{21}$

While we acknowledge the range of possible explanations for the robust finding on group size, we favor the explanation based on gender-specific dating utilities for the reasons given above. We now provide a more structured theoretical discussion of the Speed Dating game.

\section{Theoretical Analysis}

Our theoretical framework is designed to identify the conditions that are sufficient to justify our interpretations of the results in the previous two sections. Many issues that are undeniably important in dating markets we ignore in order to preserve tractability. Most importantly, we do not explicitly model matching with learning. As Das and Kamenica [2005] observe, matching with learning is a two-sided $n$-armed bandit problem so solving for equilibria can be prohibitively difficult. Therefore, we present a simplified model more directly tailored to our empirical analysis.

Let $\mathcal{M}=\{1,2, \ldots, N\}$ be the set of men and $\mathscr{W}=\{N+$ $1, \ldots, 2 N\}$ be the set of women present on a particular evening. $v_{i j}$ is the value of individual $j$ to individual $i$. For each person $i$, the $v_{i j}$ 's are drawn from some distribution $F_{i}(\cdot)$. An implicit assumption in many models of marriage, from Becker [1973] to Smith [2002], is sexwide homogeneity of preferences: $v_{i j}=v_{j}$ $\forall i \in \mathcal{M} \forall j \in \mathcal{W}$ and $v_{i j}=v_{j} \forall i \in \mathscr{W} \forall j \in \mathcal{M}^{22}$ We refrain from this assumption since we are interested in how a person's taste for a particular characteristic varies with that person's own characteristics (as in Tables IV and V). In particular, we take these values to be functions of certain attributes. Let each individual have $K$ attributes, and let $a_{i j k}$ denote individual $i$ 's appreciation

21. Ordering also does not affect our attribute weight results. All of our reported results are robust to the inclusion of fixed effects for each meeting number. Similarly, we find no significant interactions of attributes with time in predicting decisions.

22. We borrow this terminology, as well as our basic notation, from Das and Kamenica [2005]. 
of $j$ 's endowment of attribute $k$. The $v_{i j}$ 's are then functions of these attribute valuations: $v_{i j}=f_{i}\left(a_{i j 1}, \ldots, a_{i j k}\right)$.

After observing the attributes of everyone at the Speed Dating session, ${ }^{23}$ each person says Yes to those with whom they want a date. If a man and a woman say Yes to each other, they go out on a date. ${ }^{24}$ If man $i$ goes out on dates with women $W \subset W$, he receives utility $U_{i}\left(\left\{v_{i j}, v_{j i}\right\}_{j \in W}\right)$ while woman $i$ receives utility $U_{i}\left(\left\{v_{i j}, v_{j i}\right\}_{j \in M}\right)$ from going out with men $M \subset M$. We allow the utility function of person $i$ to depend on how much the dates like him or her because this might influence the chances of forming a subsequent relationship with a date. ${ }^{25}$ We can thus think of Section III as primarily concerned with identifying the value functions $(f)$, while Section IV studies the utility functions $(U)$.

Identifying the value function $f$ is much easier if Yeses are given to individuals with higher values; i.e., if whenever $i$ says Yes to $j$ and No to $j^{\prime}$ we have $v_{i j}>v_{i j^{\prime}}$. We call such behavior straightforward. Equilibrium behavior need not be straightforward in general. In particular, individual $i$ might not engage in straightforward behavior if ( $\mathrm{s}$ )he primarily cares about the utility from a subsequent relationship that may ultimately result from a date, i.e., match utility, rather than the flow utility from the dates, i.e., dating utility, and thus avoids highly valued individuals who would go out on a date with $i$ but would never engage in a subsequent relationship with him or her. By contrast, when an individual cares only about the dating utility and there are no complementarities in dating any two individuals, we expect to observe straightforward behavior in equilibrium. Consider a situation where individual $i$ has a utility function of the form,

$$
U_{i}\left(\left\{v_{i j}, v_{j i}\right\}_{j \in X}\right)=\sum_{k=1}^{|X|} u^{k}\left(V_{i j k}\right)-C(|X|),
$$

where $|X|$ is the cardinality of $X,\left\{j_{1}, \ldots, j_{|X|}\right\}=X, v_{i j_{k}} \geq v_{i j_{k+1}}$, $u^{k} \geq u^{k+1}, C^{\prime} \geq 0$ and $\left(u^{k}\right)^{\prime} \geq 0 \forall k$. In other words, person $i$ 's

23. Of course some, if not all, attributes are observed only imperfectly, especially given the brevity of the meetings. As we mentioned earlier, however, we do not model this noise explicitly in order to avoid the intractability induced by simultaneous matching and learning.

24. Our follow-up survey indicates that approximately half of all matches led to subsequent dates within three weeks of the event.

25 . Note that this formulation excludes the possibility of disutility from knowledge of rejection. We recognize that fear of rejection is a substantive assumption, but believe that the experimental design minimizes this concern due to the lack of direct personal feedback. 
utility is the sum of the values of his or her dates, with decreasing value of lower-ranked partners, minus a cost that is increasing in the total number of dates. The key assumptions underlying this formulation are (i) the cost of saying Yes derives purely from the cardinality of the number of dates; (ii) the benefit function is separable across individuals; and (iii) utility is derived from dating alone. Utility functions of this form trivially lead to straightforward behavior.

Proposition 1. Suppose that $U_{i}\left(\left\{v_{i j}, v_{j i}\right\}_{j \in X}\right)=\sum_{k=1}^{|X|} u^{k}\left(v_{i j_{k}}\right)-C(|X|)$, where $\left\{j_{1}, \ldots, j_{|X|}\right\}=X, v_{i j_{k}} \geq v_{i j_{k+1}}, u^{k} \geq u^{k+1}, C^{\prime} \geq 0$ and $\left(u^{k}\right)^{\prime}$ $\geq 0 \forall k$. Then, there is an equilibrium where $i$ engages in straightforward behavior.

The proof is in the Appendix. This equilibrium is not unique since it is costless for $i$ to say Yes to undesirable individuals who do not say Yes to $i .^{26}$ In fact, however, only a very small number of our subjects say Yes to all partners (ten males and six females).

When individuals engage in straightforward behavior, we can use their Yes/No decisions to infer their value functions, but we also may learn something about the nature of the utility functions $(U)$ from the elasticity of their number of Yeses with respect to group size. In particular, when the benefit of dates is more concave, i.e., the difference between $u^{k}$ and $u^{k+1}$ is greater, or the cost of dates is more convex, i.e., $C^{\prime \prime}(\cdot)$ is more positive, selectivity will increase more strongly with group size. In other words, increasing marginal costs or decreasing marginal benefits leads to a lower net return from more dates, so a greater abundance of potential partners is less likely to translate into a desire for more dates.

We highlight that without the conditions that yield straightforward behavior underlying preferences cannot be inferred from subjects' choices without an explicit model of the strategic environment. The assumption of straightforward behavior is a substantive caveat to be considered in interpreting the evidence we have presented.

26. Note that we cannot obtain a unique straightforward equilibrium even if we require trembling-hand perfection. 


\section{CONCLUSION}

Our paper serves as an important starting point in understanding the preferences underlying the search for a mate. Prior work in economics has emphasized final matches, but the theory and empirics have not been well-suited to the study of how these matches are actually formed. In this paper we utilize an experimental design that allows us to directly observe individual decisions and develop a formal model that establishes the conditions under which a regression framework is appropriate for estimating preferences over partner attributes.

There are a number of ways that our work may be improved upon to generate more refined measures of preferences for romantic partners. Most notably, a similar methodology could be employed on a broader set of subject populations to examine the extent to which our gender asymmetry results generalize. Such experiments could also be used to better understand the differences across communities in dating preferences. A second important extension will be to develop data sets that similarly identify individual preferences, but focus on longer run outcomes and relationship formation.

Extensions to our theoretical analysis would also be useful for a better understanding of dating markets. In particular, incorporating uncertainty and learning, which are especially relevant in the longer run, is an important next step for theory. More ambitiously, we hope to develop models that incorporate strategic behavior into dating decisions.

A deeper understanding of dating preferences is an essential input for examining a number of social issues. Topics ranging from race relations to intergenerational mobility strongly depend on outcomes in the marriage market. The equilibrium household formation in turn derives from the underlying preferences for romantic partners. Prescriptively, a more complete and better calibrated theory of dating preferences, built on results such as those we report above, may eventually allow us to evaluate different institutional arrangements for generating matches.

\section{APPENDIX}

Proof of Proposition 1. Let $Y$ be the set of individuals that say Yes to $i$. Then, regardless of the behavior of other individuals of $i$ 's gender, a best response for $i$ is to say Yes to $\left\{j_{1} \ldots, j_{m}\right\} \subset Y$, subject 
to $v_{i j_{k}} \geq v_{i j_{k+1}}, u^{m}\left(v_{i j_{m}}\right) \geq C(m)-C(m-1)$ and $u^{m+1}\left(v_{i j^{\prime}}\right) \leq$ $C(m+1)-C(m) \forall j^{\prime} \in Y-\left\{j_{1}, \ldots, j_{m}\right\}$. In other words, $i$ says Yes to $m$ individuals (s)he likes the best out of the set $Y$, where $m$ is the largest number such that the marginal utility of the $m$ th individual exceeds his or her marginal cost. Therefore, all the individuals to whom $i$ says Yes (s)he values more than those to whom (s)he says No.

Graduate School of Business, Columbia University Graduate School of Business, Columbia University DEPARTMENT OF ECONOMICS, HARVARD UNIVERSITY

Graduate School of Business, Stanford University

\section{REFERENCES}

Becker, Gary S., "A Theory of Marriage: Part I," Journal of Political Economy, LXXXI (1973), 813-846.

Bisin, Alberto, Giorgio Topa, and Thierry Verdier, "Religious Intermarriage and Socialization in the United States," Journal of Political Economy, CXII (2004), 615-664.

Burdett, Kenneth, and Melvyn Coles, "Marriage and Class," Quarterly Journal of Economics, CXII (1997), 141-168.

Buss, David M., "Toward an Evolutionary Psychology of Human Mating," Behavioral and Brain Sciences, XII (1989), 39-49.

_- "The Strategies of Human Mating," American Scientist, LXXXII (1994), $238-249$.

Buss, David M., and David P. Schmitt, "Sexual Strategies Theory: An Evolutionary Perspective on Human Mating," Psychological Review, C (1993), 204-232.

Buss, David M., and Douglas T. Kenrick, "Evolutionary Social Psychology," in Daniel T. Gilbert, ed., The Handbook of Social Psychology, 4th ed., Vol. 2 (Boston, MA: McGraw-Hill, 1998), pp. 982-1026.

Clark, Russell D., and Elaine Hatfield, "Gender Differences in Receptivity to Sexual Offers," Journal of Psychology and Human Sexuality, II (1989), 39-55.

Das, Sanmay, and Emir Kamenica, "Two-Sided Bandits and the Dating Market," Proceedings of the Nineteenth International Joint Conferences on Artificial Intelligence (2005), 947-952.

Dowd, Maureen, "Men Just Want Mommy," The New York Times, January 13, 2005.

Eagly, Alice H., Sex Differences in Social Behavior: A Social-Role Interpretation (Hillsdale, NJ: Erlbaum, 1987).

Eagly, Alice H., and Wendy Wood, "The Origins of Sex Differences in Human Behavior: Evolved Dispositions versus Social Roles," American Psychologist, LIV (1999), 408-423.

Fisman, Raymond, Sheena Iyengar, Emir Kamenica, and Itamar Simonson, "Racial Preferences in Dating: Evidence from a Speed Dating Experiment," Working Paper, 2005.

Hitsch, Gunter, Ali Hortacsu, and Dan Ariely, "What Makes You Click: An Empirical Analysis of Online Dating," Working Paper, 2004.

Kenrick, Douglas T., and Richard C. Keefe, "Age Preferences in Mates Reflect Sex Differences in Human Reproductive Strategies," Behavioral and Brain Sciences, XV (1992), 75-91.

Kerckhoff, Alan C., and Keith E. Davis, "Value Consensus and Need Complementarity in Mate Selection," American Sociological Review, XXVII (1962), 295-303.

Mortensen, Dale T., and Christopher A. Pissarides, "New Developments in Models of Search in the Labor Market," in O. Ashenfelter and D. Card, eds., Hand- 
book of Labor Economics, Vol. 3 (Amsterdam: Elsevier Science, 1999), pp. 2567-2627.

Murstein, Bernard I., "Stimulus-Value Role: A Theory of Marital Choice," Journal of Marriage and the Family, XXXII (1970), 465-481.

Regan, Pamela, "Minimum Mate Selection Standards as a Function of Perceived Mate Value, Relationship Context, and Gender," Journal of Psychology and Human Sexuality, X (1998), 53-73.

Regan, Pamela C., Lauren Levin, Susan Sprecher, F. Scott Christopher, and Rodney Cate, "Partner Preferences: What Characteristics Do Men and Women Desire in Their Short-Term Sexual and Long-Term Romantic Partners?" Journal of Psychology and Human Sexuality, XII (2000), 1-21.

Shimer, Robert, and Lones Smith, "Assortative Matching and Search," Econometrica, LXVIII (2000), 343-369.

Simonson, Itamar, and Stephen Nowlis, "The Effect of Explaining and Need for Uniqueness on Consumer Decision Making: Unconventional Consumer Choices Based on Reasons," Journal of Consumer Research, XXVII (2000), $49-68$.

Smith, Lones, "The Marriage Model with Search Frictions," Working Paper, 2002.

Stewart, Stephanie, Heather Stinnett, and Lawrence B. Rosenfeld, "Sex Differences in Desired Characteristics of Short-Term and Long-Term Relationship Partners," Journal of Social and Personal Relationships, XVII (2000), 843-853.

Symons, Donald, The Evolution of Human Sexuality (New York: Oxford University Press, 1979).

Wilson, Timothy D., and Jonathan W. Schooler, "Thinking Too Much: Introspection Can Reduce the Quality of Preferences and Decisions," Journal of Personality and Social Psychology, LX (1991), 181-192.

Wong, Linda Y., "Structural Estimation of Marriage Models," Journal of Labor Economics, XXI (2003), 699-728. 